\title{
Superação da dormência de sementes de Enterolobium contortisiliquum (Vell.) Morong com utilização de calor seco
}

\author{
Débora de Melo Almeida ${ }^{1 *}$, João Gilberto Meza Ucella Filhoํㅜ, Sarah Rebeka Rodrigues \\ Marques ${ }^{1}$, Tatiane Kelly Barbosa de Azevêdo ${ }^{1}$
}

\begin{abstract}
RESUMO: Propondo novas alternativas para a superação da dormência de sementes de espécies florestais nativas, este trabalho teve como objetivo avaliar o efeito do uso do calor seco na emergência de sementes de Enterolobium contortisiliquum. O trabalho foi conduzido na casa de vegetação da Unidade Acadêmica Especializada em Ciências Agrárias (UAECIA), durante o mês de novembro de 2016. Os frutos foram obtidos de matrizes, localizadas no município de Macaíba - RN e foram beneficiados manualmente. As sementes foram acondicionadas em papel alumínio e conduzidas a estufa com circulação forçada de ar, apresentando temperatura igual a $60^{\circ} \mathrm{C}$, durante diferentes períodos de tempo $(5,10,15$ e $20 \mathrm{~min})$. Posteriormente, as sementes foram conduzidas a casa de vegetação e colocadas para emergir em bandejas de plástico, contento areia lavada e foram irrigadas diariamente. O delineamento experimental utilizado foi o inteiramente casualizado. A escarificação mecânica e a exposição das sementes durante 5 minutos ao calor seco, mostraram-se como os métodos mais eficientes para a superação da dormência tegumentar. A exposição de sementes de Enterolobium contortisiliquum ao calor seco, é uma alternativa viável para melhoria do seu poder germinativo, sendo necessário o aprimoramento do tempo de permanência em estufa e da temperatura adequada.
\end{abstract}

Palavras-chave: impermeabilidade do tegumento, emergência, espécie nativa

\section{Overcoming of dormancy in seeds of Enterolobium contortisiliquum (Vell.) Morong using dry heat}

\begin{abstract}
Proposing new alternatives to overcome seed dormancy of native forest species, this study aimed to evaluate the effect of dry heat on emergence of Enterolobium contortisiliquum (Vell.) Morong seeds. The work was carried out in the greenhouse of the Academic Unit Specialized in Agricultural Sciences (UAECIA) during the month of November 2016. The fruits were obtained from matrices, located in the municipality of Macaíba - RN, and benefited manually. The seeds were conditioned in aluminum foil and forced to the oven with $60^{\circ} \mathrm{C}$ for different periods of time $(5,10,15$ and $20 \mathrm{~min})$. Afterwards, the seeds were taken to greenhouse and placed to emerge in plastic trays, containing washed sand and irrigated daily. The experimental design was completely randomized. Mechanical scarification and seed exposure for 5 minutes under dry heat proved to be the most efficient methods for overcoming integument dormancy. . The exposure of Enterolobium contortisiliquum seeds to dry heat is a viable alternative to improve their germinative power, and it is necessary to improve the residence time and the appropriate temperature.
\end{abstract}

Keywords: impermeability of tegument, emergency, native specie

\section{INTRODUÇÃO}

Enterolobium contortisiliquum (Vell.) Morong, é uma espécie arbórea nativa, pertencente à família Fabaceae, subfamília Mimosoideae, conhecida popularmente como tamboril, timbaúva ou orelhade-macaco, a qual encontra-se amplamente distribuída nas formações florestais brasileiras, ocorrendo desde a região Amazônica até o Rio Grande do Sul, com predominância nas florestas latifoliadas na bacia do rio Paraná (LIMA, et al., 2009; LORENZI, 1992). De acordo com Durigan et al. (2002), consiste em uma árvore de grande porte e crescimento rápido, heliófila e secundária inicial, quanto à sua classificação no estágio sucessional, sendo encontrada, frequentemente, colonizando áreas desmatadas, de clareiras e bordas de mata.

A espécie é amplamente empregada na fabricação de barcos, canoas, brinquedos, armação de móveis e caixotarias, em decorrência da leveza da sua madeira (LORENZI, 1998). Além disso, pode ser utilizada na construção civil; na medicina popular, em razão da casca do caule e o fruto apresentarem propriedades anti-inflamatórias e 
antibióticas, respectivamente; no paisagismo, para a ornamentação de praças e reflorestamentos de áreas degradadas, em especial por seu rápido crescimento (SANTOS, 1987; AGRA et al., 2007). No entanto, a exploração intensiva para utilização em serrarias, construção naval e civil, dentre outros setores da economia, contribuem para com a diminuição das populações naturais.

A multiplicação por sementes é lenta e desuniforme devido o mecanismo de dormência presente no tegumento, tornando-o impermeável e impedindo a absorção de água, sendo imposta uma restrição mecânica ao crescimento do embrião, retardando o processo germinativo (ALCALAY, AMARAL, 1982; FERREIRA et al., 1992), mesmo que as sementes estejam intactas, viáveis e expostas a condições ambientais favoráveis (FERREIRA, BORGHETTI, 2004), acarretando na baixa eficiência da regeneração natural quando observada em um curto período de tempo.

Em relação a produção de mudas florestais, a dormência tegumentar é considerada uma característica indesejada para os produtores, visto que pode dificultar e/ou inviabilizar a germinação (LEMOS FILHO et al., 1997). Sendo assim, diante da urgente necessidade de produção de mudas para a recomposição da vegetação nativa e recuperação de áreas degradadas, são recomendados alguns métodos para a superação da dormência de sementes, que incluem tratamentos químicos, escarificação mecânica e tratamento térmico, através do uso de temperaturas elevadas. Vale salientar, que as espécies tropicais respondem de maneira mais eficiente aos métodos que utilizam exposição ao calor, pois simulam as condições ambientais pelas quais as sementes estão expostas no seu "habitat" natural (SANTOS, SANTOS, 2010; GARCIA, BASSEGIO, 1999).

A utilização do calor seco é um método alternativo que vem sendo empregado na superação da impermeabilidade do tegumento, que consiste na exposição das sementes à alta temperatura, podendo ser considerado satisfatório, prático e não prejudicial; além do mais, é possível utilizá-lo em larga escala, em razão da facilidade de aplicação e os riscos e dificuldades são muito reduzidos ou quase inexistentes (WUTKE et al., 1995; CASTRO, 2010).

Logo, em razão da escassez de trabalhos propondo novas alternativas para a superação da dormência de sementes de espécies florestais nativas, este trabalho teve como objetivo avaliar o efeito do uso do calor seco na superação da dormência de sementes de Enterolobium contortisiliquum.

\section{MATERIAL E MÉTODOS}

O presente trabalho foi conduzido na casa de vegetação da Unidade Acadêmica Especializada em Ciências Agrárias (UAECIA), localizada na Escola Agrícola de Jundiaí (EAJ), Campus de Macaíba, da Universidade Federal do Rio Grande do Norte (UFRN), durante o mês de novembro de 2016. De acordo com a classificação climática de Köppen, o clima local é caracterizado como tropical chuvoso, ou seja, uma transição entre os tipos As e BSw, apresentando estação chuvosa de outono e inverno, com temperatura média de $27^{\circ} \mathrm{C}$, umidade relativa média anual de $76 \%$ e precipitação pluviométrica variando entre 863,7 e 1.070,7 mm (IDEMA, 2013).

Os frutos dos quais extraiu-se as sementes, foram obtidos de matrizes, localizadas no município de Macaíba - RN. O beneficiamento dos frutos foi feito manualmente, com o auxílio de um alicate. As sementes de Enterolobium contortisiliquum foram acondicionadas em papel alumínio e conduzidas a estufa com circulação forçada de ar, apresentando temperatura igual a $60^{\circ} \mathrm{C}$, durante diferentes períodos de tempo. Os tratamentos utilizados foram o controle (T0): escarificação mecânica; tratamento 1 (T1): 5 min. em estufa a $60^{\circ} \mathrm{C}$; tratamento 2 (T2): $10 \mathrm{~min}$. em estufa a $60^{\circ} \mathrm{C}$; tratamento 3 (T3): 15 min. em estufa a $60^{\circ} \mathrm{C}$; tratamento 4 (T4): $20 \mathrm{~min}$. em estufa a $60^{\circ} \mathrm{C}$. No tratamento controle utilizou-se a escarificação mecânica, porque de acordo com Malavasi, C. U. e Malavasi, M. M. (2004), é um método altamente eficaz e comumente empregado na superação da dormência tegumentar de sementes de Enterolobium contortisiliquum, obtendo-se uniformidade no processo germinativo. Posteriormente, as sementes foram conduzidas a casa de vegetação e colocadas para emergir em bandejas de plástico, contento areia lavada e foram irrigadas diariamente.

$\mathrm{O}$ delineamento experimental utilizado foi o inteiramente casualizado, com quatro tratamentos, os quais apresentavam seis repetições de 10 sementes por tratamento. As sementes foram observadas diariamente, após a instalação do experimento, adotando-se como critério para a avaliação da emergência a emissão dos cotilédones, sendo as variáveis avaliadas: percentagem de emergência e índice de velocidade de emergência (IVE). Os dados foram analisados estatisticamente no software ASSISTAT, os quais foram submetidos ao teste de normalidade de Lilliefors. Em seguida, realizou-se a análise de variância de Kruskal-Walls, sendo as médias comparadas pelo teste de Dunn a 5\% de probabilidade. 


\section{RESULTADOS E DISCUSSÕES}

Os valores médios encontrados para a percentagem de emergência e o índice de velocidade de emergência de sementes de Enterolobium contortisiliquum, submetidas aos tratamentos para a superação da dormência tegumentar, seguidos do teste de médias de Dunn a 5\% de probabilidade, são mostrados na Tabela 1. Em relação a percentagem de emergência, a escarificação mecânica, o método comumente utilizado para a superação da dormência tegumentar de sementes florestais, foi igual a $27,5 \%$ e o índice de velocidade de emergência igual a 27,5. Enquanto que nos tratamentos onde as sementes foram expostas ao calor seco durante diferentes períodos de tempo, os resultados obtidos foram $16,75 \%, 12 \%, 8,25 \%$ e $13 \%$, quanto a percentagem de emergência e $17,25,10,41,9,66$ e 12,66 , para o índice de velocidade de emergência, respectivamente.

A escarificação mecânica e a exposição das sementes durante 5 minutos ao calor seco, mostraram-se como os métodos mais eficientes para a superação da dormência tegumentar de sementes de Enterolobium contortisiliquum, não diferindo estatisticamente entre si. No entanto, a percentagem de emergência obtida expondo-se as sementes ao calor seco, foi inferior a encontrada utilizando-se a escarificação mecânica. Os demais tratamentos, que variaram quanto ao tempo de exposição das sementes ao calor seco, não apresentaram diferença estatística para com o tratamento $2\left(5 \mathrm{~min} .-60^{\circ} \mathrm{C}\right)$ e entre si, indicando que a utilização do calor seco pode ser considerado um método promissor para a superação da dormência tegumentar de sementes da espécie em estudo, diante da adequação do período de permanência das sementes em estufa e da temperatura a ser utilizada.

No trabalho desenvolvido por Silva e Rosa (2012), constatou-se que a escarificação mecânica foi o método mais eficiente para a superação da dormência tegumentar de sementes de Enterolobium contortisiliquum, obtendo-se $100 \%$ da germinação e valor igual a 12,77 para o índice de velocidade de emergência (IVE), o qual consistiu no maior valor obtido, inferior ao encontrado neste trabalho, que foi de 27,5, podendo estar associado a diversos fatores, dentre eles a variabilidade genética da espécie, as condições edafoclimáticas, o modo e o tempo de armazenamento, os quais afetam diretamente no vigor das sementes. Nos tratamentos que expuseram as sementes ao calor seco a $65^{\circ} \mathrm{C}$, durante $12,24 \mathrm{e}$ $48 \mathrm{~h}$, observou-se que a percentagem de germinação aumentou gradativamente, conforme elevou-se o período de permanência das sementes na estufa. No entanto, neste estudo a percentagem de emergência foi superior no tratamento que expôs as sementes durante curto período de tempo ao calor seco.

Tabela 1 - Percentagem de emergência e índice de velocidade de emergência (IVE) de sementes de Enterolobium contortisiliquum submetidas ao calor seco durante diferentes períodos de tempo para superação da dormência.

\section{TRATAMENTOS}

EMERGÊNCIA $(\%)$

IVE

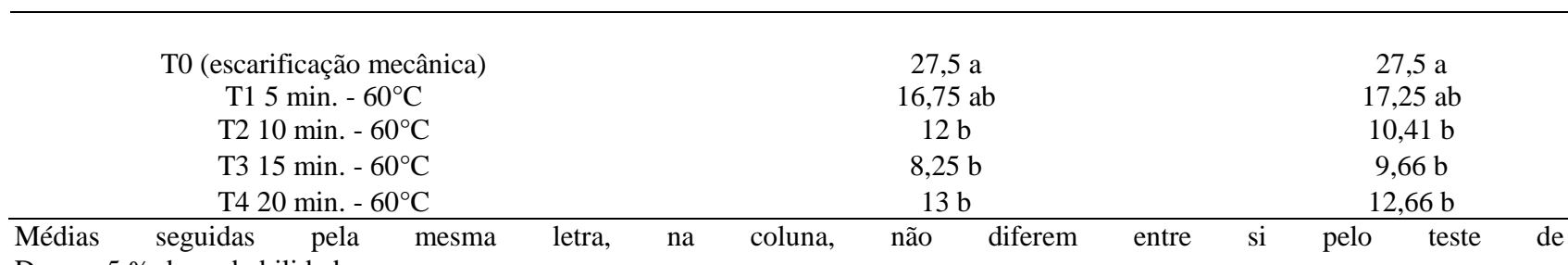

Dunn a $5 \%$ de probabilidade.

A escarificação mecânica também apresentou eficiência em estudos desenvolvidos por Andreani Junior et al. (2014), Ferreira et al. (2013) e Silva et al. (2012), os quais avaliaram diferentes métodos para a superação da dormência de sementes de Enterolobium contortisiliquum, obtendo-se em torno de $88 \%$, $63 \%$ e $25 \%$ de germinação, respectivamente.

A dormência imposta pelo tegumento, é comumente encontrada em sementes de espécies florestais pertencentes a família Fabaceae (OLIVEIRA et al., 2003). De acordo com Zaidan e Barbedo (2004), a escarificação mecânica têm-se mostrado como um dos métodos mais eficientes para a superação da dormência nos casos de impermeabilidade do tegumento, pois promove a entrada de água nas sementes, acarretando na reativação dos processos metabólicos (BORGES, RENA, 1993).

No entanto, para utilizar esse método em grandes quantidades de sementes, são necessários equipamentos específicos, pois a escarificação manual demanda tempo e mão-de-obra, inviabilizando o processo (SILA, ROSA, 2012). Logo, torna-se necessário a implementação de novas técnicas práticas e satisfatórias, sendo a utilização do calor seco uma opção viável, pois pode promover a retração do tegumento em várias espécies; porém, 
devido à escassez de estudos, essa técnica carece de aprimoramento da temperatura e do tempo de permanência ideal de exposição das sementes ao calor seco (PEREIRA, FERREIRA, 2010).

\section{CONCLUSÕES}

A exposição de sementes de Enterolobium contortisiliquum ao calor seco, é uma alternativa viável para melhoria do seu poder germinativo, sendo necessário o aprimoramento do tempo de permanência em estufa e da temperatura adequada.

\section{REFERÊNCIAS}

AGRA, M. F.; BARACHO, G. S.; BASÍLIO, I. J. D.; NURIT, K.; COELHO, V. P.; BARBOSA, D. A. Sinopse da flora medicinal do cariri paraibano. Oecologia brasiliensis, Rio de Janeiro, v. 11, n. 3, p. 323-330, 2007.

ALCALAY, N.; AMARAL, D.M.I. Quebra de dormência em sementes de timbaúva -Enterolobium contortisiliquum (VeII.) Morong. Silvicultura em São Paulo, 16 A, p.1149-1152, 1982.

ANDREANI JUNIOR, R.; MELLO, W. S.; SANTOS, S. R. G.; KOZUSNY-ANDREAN, D. I. Superação da dormência de sementes de três essências florestais nativas. Revista da Universidade Vale do Rio Verde, Três Corações, v. 12, n. 1, p.470-479, jan./jul. 2014.

CASTRO, D. S. Superação de dormência em sementes de garapa (Apuleia leiocarpa (Vogel) J. F. Macbr.). 63 f. Dissertação (Mestrado em Fitotecnia), Universidade Federal de Viçosa, Viçosa - MG, 2010.

CRUZ-SILVA, C. T. A.; ROSA, A. P. M. Tratamentos para superação da dormência em sementes de orelha-denegro (Enterolobium contortisiliquum (Vell.) Morong). Varia Scientia Agrárias, Cascavel - PR, v. 2, n. 2, p.79-90, jul. 2011.

DURIGAN, G. et al. Sementes e mudas de árvores tropicais. 2. ed., São Paulo: Páginas e Letras Editora e Gráfica, 2002.

FERREIRA, A. G.; BORGHETTI, F. Germinação do básico ao aplicado. Porto Alegre: Artmed, 2004.

FERREIRA, AO.; JOÃO, K.H.L.; HEUSER, E.D. Efeitos de escarificação sobre a germinação e do $\mathrm{pH}$ no crescimento de Acacia bonariensis Grill e Mimosa bimocronata (D.C.) O.K. Revista Brasileira de Fisiologia Vegetal, v.4, p.63-65, 1992.

FERREIRA, C.; LOPES, I.; LÚCIO, A. F. N. Métodos para superar dormência em sementes de Enterolobium contortisiliquum (Vell.) Morong. Engenharia Ambiental, Espírito Santo do Pinhal, v. 10, n. 1, p.043047, jan./fev. 2013.
GARCIA, É.N.; BASEGGIO, J. Poder germinativo de sementes de Desmodium incanum DC. (Leguminosae). Revista Brasileira de Agrociência, v.5, n.3, p.199-202, 1999.

LEMOS FILHO, J.P.; GUERRA, S.T.M.; LOVATO, M.B.; SCOTTI, M.R.M.M.L. Germinação de sementes de Senna macranthera, Senna multijuga e Stryphnodendron polyphyllum. Pesquisa Agropecuária Brasileira, v.32, n.4, p.357-361, 1997.

LIMA, R. S.; OLIVEIRA, P. L.; RODRIGUES, L. R. Anatomia do lenho de Enterolobium contortisiliquum (Vell.) Morong (Leguminosae-Mimosoideae) ocorrente em dois ambientes. Revista Brasileira de Botânica, São Paulo, v. 32, n. 2, p. 361-374, 2009.

LORENZI, H. Árvores brasileiras. 1.ed. São Paulo: Plantarum, 368p. 1992.

MALAVASI, U. C.; MALAVASI, M. M. Dormancy breaking and germination of Enterolobium contortisiliquum (Vell.) Morong seed. Brazilian Archives Of Biology And Technology, [s.1.], v. 47, n. 6, p.851-854, nov. 2004.

INSTITUTO DE DESENVOLVIMENTO ECONÔMICO E MEIO AMBIENTE DO RIO GRANDE DO NORTE (IDEMA). Perfil do seu município: Macaíba. IDEMA: Natal, 21 p. 2013. Disponível em: <http://adcon.rn.gov.br/ACERVO/idema/DOC/DOC0000 00000016679.PDF>. Acesso em: 03 jul. 2017.

PEREIRA, S. A.; FERREIRA, S. A. N. Superação da dormência em sementes de visgueiro-do-igapó (Parkia discolor). Acta Amazônica, Manaus, v.40, n.1, p. 151$156,2010$.

SANTOS, E. Nossas madeiras. 1.ed. Belo Horizonte: Editora Itatiaia, 313p. 1987.

SANTOS, H. M. e SANTOS, G. A. Superação de dormência em sementes de Enterolobium contortisiliquum (Vell.) Morong. Enciclopédia Biosfera, Goiânia, v. 6, n. 10, p.1-11, 2010.

SILVA, A. C. F.; SILVEIRA, L. P.; NUNES, I. G.; SOUTO, J. S. Superação de dormência de Enterolobium contortisiliquum Mor. (Vell.) Morong. Scientia Plena, Aracaju, v. 8, n. 4, p.2-6, abr. 2012.

WUTKE, E.B.; MAEDA, J.A.; PIO, R.M. Superação da dormência de sementes de mucuna-preta pela utilização de "calor seco". Sci. Agric., Piracicaba - SP, v. 3, n. 52, p.482-490, set./dez. 1995.

ZAIDAN, L. B. P.; BARBEDO, C. J. Quebra de dormência em sementes. In: FERREIRA, A. G; BORGHETTI, F. Germinação: do básico ao aplicado. Porto Alegre: Artmed, p.135-148, 2004. 